\title{
Chest Computed Tomography Scoring in Patients With Novel Coronavirus-infected Pneumonia: Correlation With Clinical and Laboratory Features and Disease Outcome
}

\author{
LUCA PUGLIESE ${ }^{1}$, FRANCESCO PAOLO SBORDONE ${ }^{1}$, FRANCESCO GRIMALDI ${ }^{1}$, FRANCESCA RICCI ${ }^{1}$, \\ FEDERICA DI TOSTO ${ }^{1}$, LUIGI SPIRITIGLIOZZI ${ }^{1}$, CARLO DI DONNA $^{1}$, MATTEO PRESICCE $^{1}$, \\ VINCENZO DE STASIO ${ }^{1}$, LEONARDO BENELLI ${ }^{1}$, FRANCESCA D'ERRICO $^{1}$, MONIA PASQUALETTO ${ }^{1}$, \\ JACOPO MARIA LEGRAMANTE ${ }^{2}$, MARCO MATERAZZO $^{3}$, MARCO PELLICCIARO $^{3}$, \\ ORESTE CLAUDIO BUONOMO ${ }^{3}$, GIANLUCA VANNI ${ }^{3}$, STEFANO RIZZA ${ }^{4}$, ALFONSO BELLIA ${ }^{4}$, \\ ROBERTO FLORIS ${ }^{1}$, FRANCESCO GARACI ${ }^{1}$ and MARCELLO CHIOCCHI ${ }^{1}$ \\ ${ }^{1}$ Department of Biomedicine and Prevention, Division of Diagnostic Imaging, \\ Tor Vergata University, and Unit of Diagnostic Imaging, Policlinico Tor Vergata, Rome, Italy; \\ ${ }^{2}$ Department of System Medicine, Tor Vergata University, and Emergency Department, Rome, Italy; \\ ${ }^{3}$ Breast Unit, Department of Surgical Science, Policlinico Tor Vergata University, Rome, Italy; \\ ${ }^{4}$ Department of System Medicine, Tor Vergata University, and \\ Department of Medical Sciences, Policlinico Tor Vergata, Rome, Italy
}

\begin{abstract}
Background/Aim: This study investigated the correlation of chest computed tomography $(C T)$, findings, graded using two different scoring methods, with clinical and laboratory features and disease outcome, including a novel clinical predictive score, in patients with novel coronavirusinfected pneumonia (NCIP). Patients and Methods: In this retrospective, observational study, CT scan of 92 NCIP patients admitted to Policlinico Tor Vergata, were analyzed using a quantitative, computed-based and a semiquantitative, radiologist-assessed scoring system. Correlations of the two radiological scores with clinical and laboratory features, the CALL score, and their association with a composite adverse outcome were assessed. Results: The two scores correlated significantly with each other $(\varrho=0.637, p<0.0001)$ and were independently associated with age, LDH, estimated glomerular filtration rate, diabetes, and with the composite outcome, which occurred in 24 patients. Conclusion: In NCIP patients, two different radiological scores correlated
\end{abstract}

This article is freely accessible online.

Correspondence to: Materazzo Marco, MD, Breast Unit, Department of Surgical Science, PTV: Policlinico Tor Vergata University, Viale Oxford 81, 00133, Rome, Italy. Tel: +39 3395685883, e-mail: mrcmaterazzo@gmail.com

Key Words: Novel coronavirus-infected pneumonia, computer tomography, radiological scores, intensive care unit, death. with each other and with several clinical, laboratory features, and the CALL score. The quantitative score was a better independent predictor of the composite adverse outcome than the semiquantitative score.

A novel coronavirus termed severe acute respiratory syndrome coronavirus 2 (SARS-CoV-2) was identified as the cause of the pneumonia outbreak that started in the city of Wuhan, the capital of the Hubei province in China, in December 2019 (1), and rapidly spread throughout China and to many other countries all over the world, including Italy (2). On March 11, 2020, the World Health Organization declared the disease, called COronaVirus Disease 19 (COVID-19), as a pandemic (3).

COVID-19 is a multiorgan, potentially lethal disease, whose main manifestation is an interstitial pneumonia, called novel coronavirus-infected pneumonia (NCIP) (4), which can be diagnosed by chest X-rays and particularly computed tomography (CT) (5). It has been suggested that chest CT could be used as a primary tool for the screening and diagnosis of COVID-19. A meta-analysis of 68 studies showed that pooled sensitivity and specificity of chest CT were $94 \%$ and $37 \%$, respectively, whereas sensitivity of RTPCR was $89 \%$; however, in low prevalence countries, the positive predictive value of CT was ten times lower than that of RT-PCR, which remains the gold standard (6). Nevertheless, positive CT scans were observed prior to (or concurrently with) the initial positivity of RT-PCR from swab samples in $60 \%$ to $93 \%$ of 1,014 Chinese patients (7) 
and were useful for COVID-19 diagnosis in case of falsenegative RT-PCR results (8).

Scoring systems based on either semiquantitative evaluation by expert radiologists (9-11) or quantitative, software-based image analysis (9-11) have been developed for grading the extent and severity of lung involvement in COVID-19 patients on CT scans. Radiological scores have been shown to correlate with the main clinical and laboratory features of COVID-19 and to predict disease severity and progression (9-12).

This study aimed at investigating the correlation of chest CT findings, graded using two different radiological scoring systems, with clinical and laboratory features and disease outcome, including The CALL [comorbidity, age, lymphocytes, and lactate dehydrogenase (LDH)] score, a novel clinical score for predicting risk of COVID-19 progression (13), in patients hospitalized for NCIP.

\section{Patients and Methods}

Design. This was a single-center retrospective, observational study investigating the correlates of chest CT findings in NCIP. The study protocol was approved by the ethics committee of Policlinico Tor Vergata (nr. 103/20, June 11, 2020), which allowed the use of demographic, clinical and imaging data in an anonymous manner for research purposes.

Patients. Ninety-two patients admitted to the Emergency Department of the Policlinico Tor Vergata, Rome, Italy, from March 2 to April 4, 2020, for suspected NCIP were considered for this analysis. Inclusion criteria were evidence of interstitial pneumonia at high-resolution CT (HRCT) imaging at entrance and positivity of a RT-PCT test for SARS CoV-2 RNA in a nasopharyngeal and oropharyngeal swab at entrance or, in case of negative results, after 24 or $72 \mathrm{~h}$ or otherwise in a bronchoalveolar lavage sample (14). Exclusion criteria were motion or breath artifacts on chest HRCT and non-confirmed NCIP diagnosis.

Chest CT scan and imaging evaluation. The HRCT volumetric acquisitions were performed on a 128-slice CT (GE Revolution EVO 64 Slice CT Scanner, GE Medical Systems, Milwaukee, WI, USA) with patients in the supine position and breath-holding following inspiration, without administration of contrast medium, using the standard HRCT parameters (tube voltage: $120 \mathrm{kV}$; tube current modulation 100-250 mAs; spiral pitch factor: 0.98; slice thickness: 1.25).

Images were obtained with both parenchymal (width $1500 \mathrm{HU}$; level $-600 \mathrm{HU}$ ) and mediastinal (width $350 \mathrm{HU}$; level $40 \mathrm{HU}$ ) window settings and then transferred to a dedicated workstation (ADW-6,7, GE-Healthcare, Madison, WI, USA) for both processing quantitative image analysis with a specific software package (Thoracic VCAR v13.1, GE Medical Systems, Madison, WI, USA) (15) and for semiquantitative evaluation. For both scoring systems, each lung was divided into three zones, i.e., upper, which includes the parenchyma above the carina; middle, which includes the parenchyma below the carina and above the inferior pulmonary vein; and lower, which includes the parenchyma below the inferior pulmonary vein.
The software-based, post-processing volumetric and densitometric parenchymal analysis allowed to automatically calculate the volume of each lung and of each of the six, automatically segmented lung zones (upper, middle, and lower in the two lungs) as well as the percentage of each volume occupied by air, normal parenchyma, ground-glass opacity, crazy paving, and consolidation, according to the color-coded range of parenchymal density, i.e., -1024/-977 Hounsfield Units (HU) (blue), -977/760 HU (black), -760/-368 HU (pink), -368/-135 HU (white), and $-135 /-40 \mathrm{HU}$ (red), respectively. The cumulative percentages of crazy paving and consolidation (white and red colors) in each lung and each of the six zones were then calculated as an index of the extent of parenchymal involvement. Finally, two-lung total, upper, middle, and lower volume and percent attenuation values were calculated.

The HRCT scans were independently evaluated by two radiologists with 6 and 12 years of experience, respectively, blinded of the results of the above analysis, with a final score reached by consensus in case of discrepancy. The HRCT scans were scored on the axial images according to Yuan et al. (11). Each of the 6 zones was scored separately using a 3-point scale for CT features, i.e., 1 for normal attenuation, 2 for ground-glass opacity, and 3 for consolidation, and a 4-point scale for parenchymal distribution of lesions (ground-glass opacity or consolidation), i.e., 0 for no, 1 for $<25 \%, 2$ for $25-50 \%, 3$ for $50-75 \%$, and 4 for $>75 \%$ distribution. The final scores for each zone were calculated by multiplying the two scores and then summed to obtain a total score, ranging from 0 to 72 . The $\mathrm{CT}$ features were defined according to the recommendations of the Nomenclature Committee of the Fleischner Society (16), i.e., ground-glass opacity as a hazy attenuation that does not obscure the underlying bronchial structures or pulmonary vessels and consolidation as a homogeneous opacity obscuring underlying bronchial and vascular structures. Other CT features were also recorded, i.e., crazy paving (a reticular pattern superimposed on ground-glass opacity, where the lines of reticular opacities may represent interlobular or intralobular septal thickening); consolidation with or without air bronchogram (pattern of air-filled bronchi on a background of opaque airless lung); mono or bilateral involvement; peripheral, central or diffuse parenchymal distribution; which and how many lung lobes were involved; mediastinum lymphadenopathy (presence of at least one lymph node with short axis $>10 \mathrm{~mm}$ ); pleural and pericardial effusion (17).

Demographic, anamnestic, clinical and laboratory data. The following data were collected from patients or their relatives: current age, gender, smoking habits, comorbidities, including history of obesity, diabetes, hypertension, and cardiovascular (coronary artery disease, stroke), respiratory [asthma, chronic obstructive pulmonary disease (COPD)], oncological, and hematological disorders, and clinical presentation, including fever $>37.5^{\circ} \mathrm{C}$, sore throat, cough, dyspnea, fatigue, myalgia, chest pain, and others. The number of comorbidities was calculated and the occurrence of a composite adverse outcome including admission to intensive care unit (ICU, at entry or during hospital stay) and/or in-hospital death was assessed for each patient.

The following laboratory data were also obtained: complete blood count (hemoglobin, leukocytes, lymphocytes, and platelets), enzymes [LDH, creatine kinase muscle/brain (CK MB), highsensitivity cardiac troponin I (hs-cTn I), B-type natriuretic peptide (BNP), and lipase], D-dimer, fibrinogen, and serum creatinine. 
Pugliese et al: Clinical and CT Features in COVID-19 Patients

Table I. Main demographic, clinical and laboratory features of study subjects.

\begin{tabular}{|c|c|c|c|c|c|c|c|}
\hline Variable & $\mathrm{n}$ & All & $\mathrm{n}$ & No-ICU/no-death & $\mathrm{n}$ & ICU/death & $p$-Value \\
\hline \multicolumn{8}{|l|}{ Demographics } \\
\hline Age, years & 92 & $63.0(52.3,78.5)$ & 68 & $60.0(50.3,76-8)$ & 24 & $72.5(62.3-80.0)$ & 0.048 \\
\hline Male gender, n (\%) & 92 & 66 (71.7) & 68 & $43(63.2)$ & 24 & $23(95.8)$ & 0.002 \\
\hline Current smoker, n (\%) & 90 & $6(6.7)$ & 67 & $3(4.5)$ & 23 & $3(13.0)$ & 0.155 \\
\hline \multicolumn{8}{|l|}{ Comorbidities, n (\%) } \\
\hline Any comorbidity & 92 & $74(80.4)$ & 68 & $51(75.0)$ & 24 & $23(95.8)$ & 0.027 \\
\hline Obesity & 92 & $4(4.3)$ & 68 & $1(1.5)$ & 24 & $4(12.5)$ & 0.023 \\
\hline Diabetes & 92 & $15(16.3)$ & 68 & $8(11.8)$ & 24 & $7(29.2)$ & 0.047 \\
\hline Hypertension & 92 & $45(48.9)$ & 68 & $28(41.2)$ & 24 & $17(70.8)$ & 0.012 \\
\hline Any cardiovascular & 92 & $56(60.9)$ & 68 & $39(57.4)$ & 24 & $17(70.8)$ & 0.245 \\
\hline Coronary artery disease & 92 & $54(58.7)$ & 68 & $37(54.4)$ & 24 & $17(70.8)$ & 0.160 \\
\hline Stroke & 92 & $6(6.5)$ & 68 & $6(8.8)$ & 24 & $0(0.0)$ & 0.132 \\
\hline Any respiratory & 92 & $5(5.4)$ & 68 & $4(5.9)$ & 24 & $1(4.2)$ & 0.750 \\
\hline Asthma & 92 & $3(3.3)$ & 68 & $3(4.4)$ & 24 & $0(0.0)$ & 0.295 \\
\hline COPD & 92 & $2(2.2)$ & 68 & $1(1.5)$ & 24 & $1(4.2)$ & 0.436 \\
\hline Oncological & 92 & $8(8.7)$ & 68 & $5(7.4)$ & 24 & $3(12.5)$ & 0.442 \\
\hline Hematological & 92 & $7(7.6)$ & 68 & $2(7.4)$ & 24 & $7(8.3)$ & 0.876 \\
\hline \multicolumn{8}{|l|}{ Clinical presentation, n (\%) } \\
\hline Asymptomatic & 90 & $4(4.4)$ & 67 & $2(3.0)$ & 23 & $2(8.7)$ & 0.252 \\
\hline Symptoms for more than 4 days & 87 & $58(66.7)$ & 64 & $47(73.4)$ & 23 & $11(47.8)$ & 0.025 \\
\hline Fever $>37.5^{\circ} \mathrm{C}$ & 90 & $73(81.1)$ & 67 & $54(80.6)$ & 23 & $19(82.6)$ & 0.832 \\
\hline Sore throat & 90 & $6(6.7)$ & 67 & $5(7.5)$ & 23 & $1(4.3)$ & 0.650 \\
\hline Cough & 90 & $64(71.1)$ & 67 & $49(73.1)$ & 23 & $15(65.2)$ & 0.470 \\
\hline Dyspnea & 90 & $42(46.7)$ & 67 & $27(40.3)$ & 23 & $15(65.2)$ & 0.039 \\
\hline Fatigue & 90 & $15(16.7)$ & 67 & $13(19.4)$ & 23 & $2(8.7)$ & 0.234 \\
\hline Myalgia & 90 & $8(8.9)$ & 67 & $6(9.0)$ & 23 & $2(8.7)$ & 0.970 \\
\hline Chest pain & 90 & $5(5.6)$ & 67 & $5(7.5)$ & 23 & $0(0.0)$ & 0.178 \\
\hline Other & 90 & $8(8.9)$ & 67 & $10(14.9)$ & 23 & $4(17.4)$ & 0.778 \\
\hline \multicolumn{8}{|l|}{ Laboratory data } \\
\hline Hemoglobin, g/l & 92 & $139(122,151)$ & 68 & $139(128,150)$ & 24 & $13.8(11.4,15.2)$ & 0.290 \\
\hline Leucocytes, $n \times 10^{9} / 1$ & 92 & $7.02(5.23,9.69)$ & 68 & $6.59(4.93,8.54)$ & 24 & $9.32(5.92,14.55)$ & 0.064 \\
\hline Lymphocytes, $\mathrm{n} \times 10^{9} / 1$ & 92 & $1.01(0.69,1.56)$ & 68 & $1.02(0.71,1.53)$ & 24 & $0.98(0.56,2.28)$ & 0.062 \\
\hline Lymphocytes, \% & 92 & $16.5(9.8-23.5)$ & 68 & $16.7(10.9,24.0)$ & 24 & $14.2(5.7,22.4)$ & 0.771 \\
\hline Platelets, $\mathrm{n} \times 10^{9} / 1$ & 92 & $197(160,262)$ & 68 & $197(163,253)$ & 24 & $194(150,292)$ & 0.662 \\
\hline $\mathrm{LDH}, \mathrm{n}(\%)$ & 92 & & 68 & & 24 & & $<0.0001$ \\
\hline$\leq 250 \mathrm{U} / 1$ & & $26(28.3)$ & & $23(33.8)$ & & $3(12.5)$ & \\
\hline $251-500 \mathrm{U} / 1$ & & $52(56.5)$ & & $41(60.3)$ & & $11(45.8)$ & \\
\hline$>500 \mathrm{U} / 1$ & & $14(15.2)$ & & $4(5.9)$ & & $10(41.7)$ & \\
\hline $\mathrm{CK}$ MB, n (\%) abnormal & 79 & $14(17.7)$ & 58 & $5(8.6)$ & 21 & $14(42.9)$ & $<0.0001$ \\
\hline hs-cTn I, n (\%) abnormal & 80 & $21(26.3)$ & 59 & $9(15.3)$ & 21 & $12(57.1)$ & $<0.0001$ \\
\hline BNP, n (\%) abnormal & 67 & $21(31.3)$ & 50 & $10(20.0)$ & 17 & $11(64.7)$ & 0.001 \\
\hline Lipase, n (\%) abnormal & 76 & $11(14.5)$ & 56 & $5(8.9)$ & 20 & $6(30.0)$ & 0.021 \\
\hline D-Dimer, $\mu \mathrm{g} / 1$ & 83 & $968(704,1,546)$ & 61 & $831(547,1,274)$ & 22 & $1,166(949,2,202)$ & 0.018 \\
\hline Fibrinogen, g/l & 89 & $6.98(5.53,8.43)$ & 65 & $6.42(4.88,8.02)$ & 24 & $741(617,875)$ & 0.470 \\
\hline Creatinine, $\mu \mathrm{mol} / 1$ & 92 & $89.3(76.0,111.4)$ & 68 & $84.0(74.3,107.9)$ & 24 & $103.4(88.4,128.2)$ & 0.156 \\
\hline $\mathrm{eGFR}, \mathrm{ml} / \mathrm{min} / 1.73 \mathrm{~m}^{2}$ & 92 & $71.5(57.3,89.8)$ & 68 & $75.5(65.3,93.8)$ & 24 & $62.0(48.8,81.8)$ & 0.017 \\
\hline
\end{tabular}

Data are median (interquartile range) for continuous variables and $\mathrm{n}(\%)$ for categorical variables. ICU: Intensive care unit; COPD: chronic obstructive pulmonary disease; LDH: lactate dehydrogenase; CK MB: creatine kinase muscle/brain; hs-cTn I: high-sensitivity cardiac troponin I; BNP: B-type natriuretic peptide; eGFR: estimated glomerular filtration rate; CALL: comorbidity, age, lymphocytes, LDH.

Levels of LDH were stratified in three groups (low, $\leq 250 \mathrm{U} / \mathrm{l}$; intermediate, 251-500 U/l; and high, $>500 \mathrm{U} / 1)$, whereas those of CK MB, hs-cTn I, BNP, and lipase were classified as normal or abnormal. Glomerular filtration rate was estimated (eGFR) from serum creatinine using the Chronic Kidney Disease Epidemiology Collaboration formula.
The CALL score was calculated based on age $(\leq 60$ years $=1$ point; $>60$ years $=3$ points $)$, lymphocytes $\left(>1 \times 10^{9} / \mathrm{l}=1\right.$ point; $\leq 1 \times 10^{9} / 1=3$ points), $\mathrm{LDH}(\leq 250 \mathrm{U} / \mathrm{l}=1$ point; $251-500 \mathrm{U} / \mathrm{l}=2$ points; $>500 \mathrm{U} / \mathrm{l}=3$ points), and comorbidities (no=1 point; yes $=4$ points); patients were then stratified by CALL score category in those at low risk (scores 4-6), intermediate risk (scores 7-9) and high risk (scores 10-13) (13). 

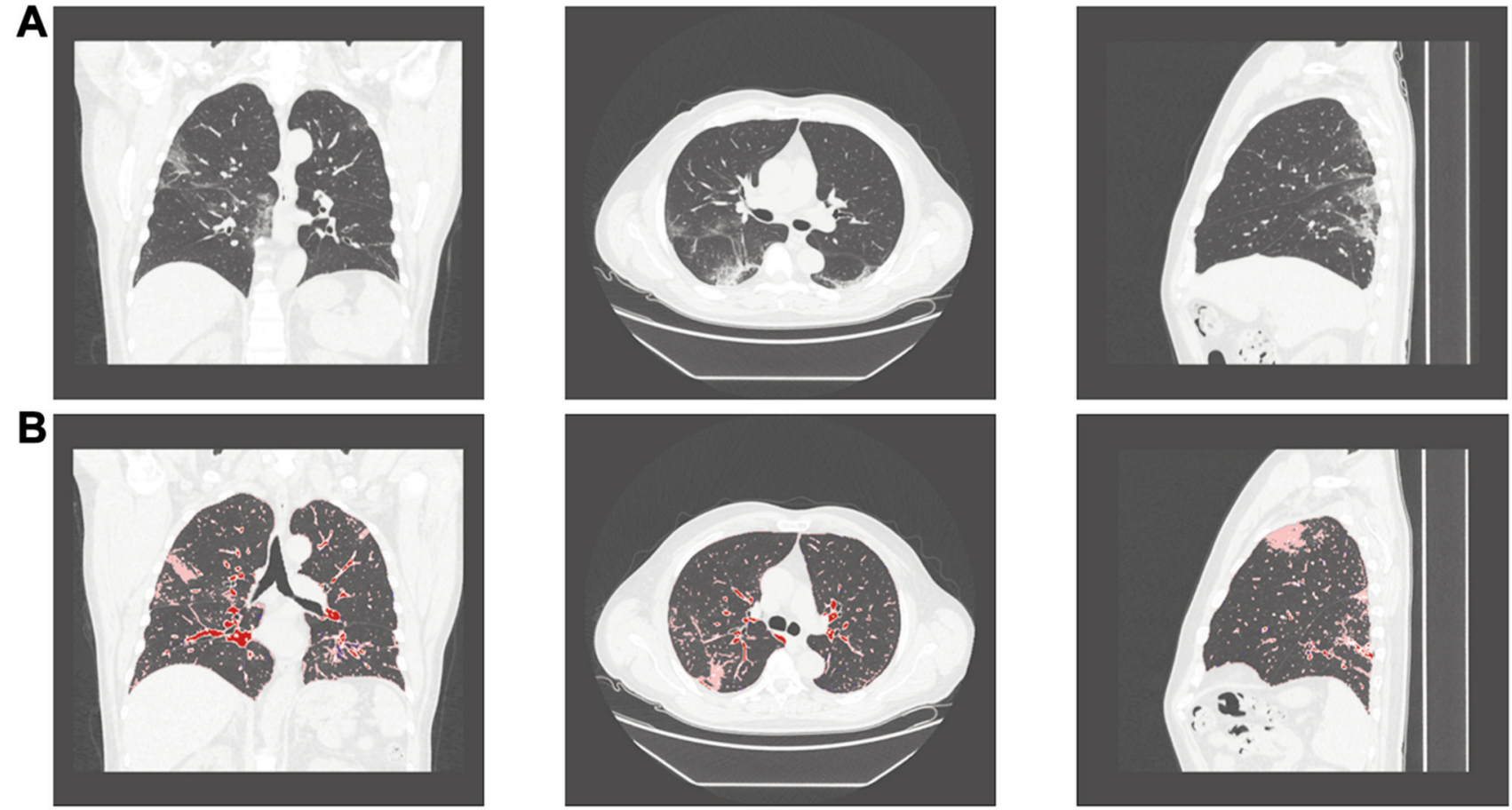

C

\begin{tabular}{|c|c|c|c|c|c|c|c|c|c|c|}
\hline \multirow{3}{*}{1} & \multirow[b]{3}{*}{ Color } & \multirow[b]{3}{*}{ HU } & & & & & & & & Mar 052020 \\
\hline & & & \multicolumn{4}{|c|}{ Right lung } & \multicolumn{4}{|c|}{ Left lung } \\
\hline & & & Total & Upper & Middle & Lower & Total & Upper & Middle & Lower \\
\hline$-950 \mathrm{HU}$ & & $\begin{array}{c}{[-1024 /} \\
.977]\end{array}$ & $0.0016 \%$ & $0.0002 \%$ & $0.0013 \%$ & $0.0034 \%$ & $0.0151 \%$ & $0.0021 \%$ & $0.032 \%$ & $0.0027 \%$ \\
\hline \multirow[t]{5}{*}{$>-950 \mathrm{HU}$} & & $\begin{array}{c}{[.977 /} \\
.760]\end{array}$ & $88.9752 \%$ & $91.4805 \%$ & $87.4205 \%$ & $88.7713 \%$ & $89.092 \%$ & $92.3241 \%$ & $89.094 \%$ & $85.7483 \%$ \\
\hline & & $\begin{array}{l}{[.760 /} \\
-368]\end{array}$ & $8,5492 \%$ & $7,3259 \%$ & $9,0021 \%$ & $9,1531 \%$ & $8,4249 \%$ & $6,9492 \%$ & $7,5865 \%$ & $11.2281 \%$ \\
\hline & & $\begin{array}{c}{[-368 /} \\
-135]\end{array}$ & $1,4325 \%$ & $0.8663 \%$ & $1,8895 \%$ & $1,3046 \%$ & $1,4333 \%$ & $0.4942 \%$ & $1.6285 \%$ & $2.1066 \%$ \\
\hline & & $\begin{array}{c}{[-135]} \\
40]\end{array}$ & $1.0415 \%$ & $0.327 \%$ & $1.6866 \%$ & $0.7676 \%$ & $1.0347 \%$ & $0.2305 \%$ & $1.6591 \%$ & $0.9143 \%$ \\
\hline & & Total & $2,8812 \mathrm{~L}$ & $0,8477 \mathrm{~L}$ & $1,2651 \mathrm{~L}$ & $0,7684 \mathrm{~L}$ & $2,3255 \mathrm{~L}$ & $0,6755 \mathrm{~L}$ & $0,9963 \mathrm{~L}$ & $0,6536 \mathrm{~L}$ \\
\hline
\end{tabular}

Figure 1. Pre-processing (A) and post-processing color-coded (B) computed tomography (CT) images, reconstructed in coronal (left), axial (middle), and sagittal (right) plane, and software-based quantification of percentage of volume occupied by air (blue), normal parenchyma (black), groundglass opacity (pink), crazy paving (white), and consolidation(red) (C) of a 69 year-old male patient not reaching the composite adverse outcome. Symptoms: fever and dyspnea. Smoking: no. Comorbidities: coronary heart disease (CHD). Main laboratory findings: lymphocytes=1.03 $n \times 10^{9} / l$ $(17.4 \%)$; lactate dehydrogenase $(L D H)=\leq 250 \mathrm{U} / \mathrm{l} ; \mathrm{D}$-dimer $1,015 \mathrm{ng} / \mathrm{ml} ;$ e GFR=66 $\mathrm{ml} / \mathrm{min} / 1.73 \mathrm{~m}^{2}$. comorbidity, age, lymphocytes, LDH $(C A L L)$ score: 9. Quantitative radiological score: total lungs=2.7\%; upper lungs=0.9\%; middle lungs=3.8\%; lower lungs=2.8\%. Semiquantitative radiological score: total lungs $=24$; upper lungs $=4$; middle lungs $=10$; lower lungs $=10$.

Statistical analysis. Data are expressed as mean \pm SD or median (interquartile range) for continuous variables, and number of cases and percentage for categorical variables.

Continuous variables were compared by Student's $t$-test or oneway ANOVA, for normally distributed variables, and by MannWhitney $U$-test or Kruskall-Wallis test, in case of variables with a skewed distribution; Bonferroni correction or Mann-Whitney test, respectively, were used for post-hoc comparisons. Pearson chisquare was applied to categorical variables.

Univariate correlations between each radiological score and the clinical and laboratory features were assessed by Spearman's rho. One-way ANOVA, for normally distributed variables, and Kruskall-Wallis test, in case of variables with a skewed distribution, were applied to assess changes in clinical and laboratory findings according to quartiles of each of the two radiological scores.

Multivariate linear regression analyses with stepwise backward selection of variables were applied to assess the independent correlates of the two scores. Covariates were age, gender, smoking status (yes/no), number of comorbidities (or presence or each of them), and selected laboratory findings (percent lymphocytes, LHD categories, D-dimer, and eGFR) or gender, smoking status, D-Dimer, eGFR, and CALL score.

Finally, multivariate binary logistic analysis with stepwise backward selection of variables was applied to assess whether the two radiological scores were independently associated with the composite adverse outcome. Covariates were the same as above, except for male gender, as the convergence of the models was not achieved when including this variable. 
A

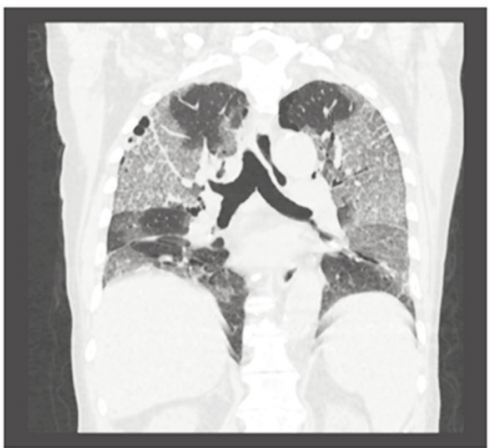

B
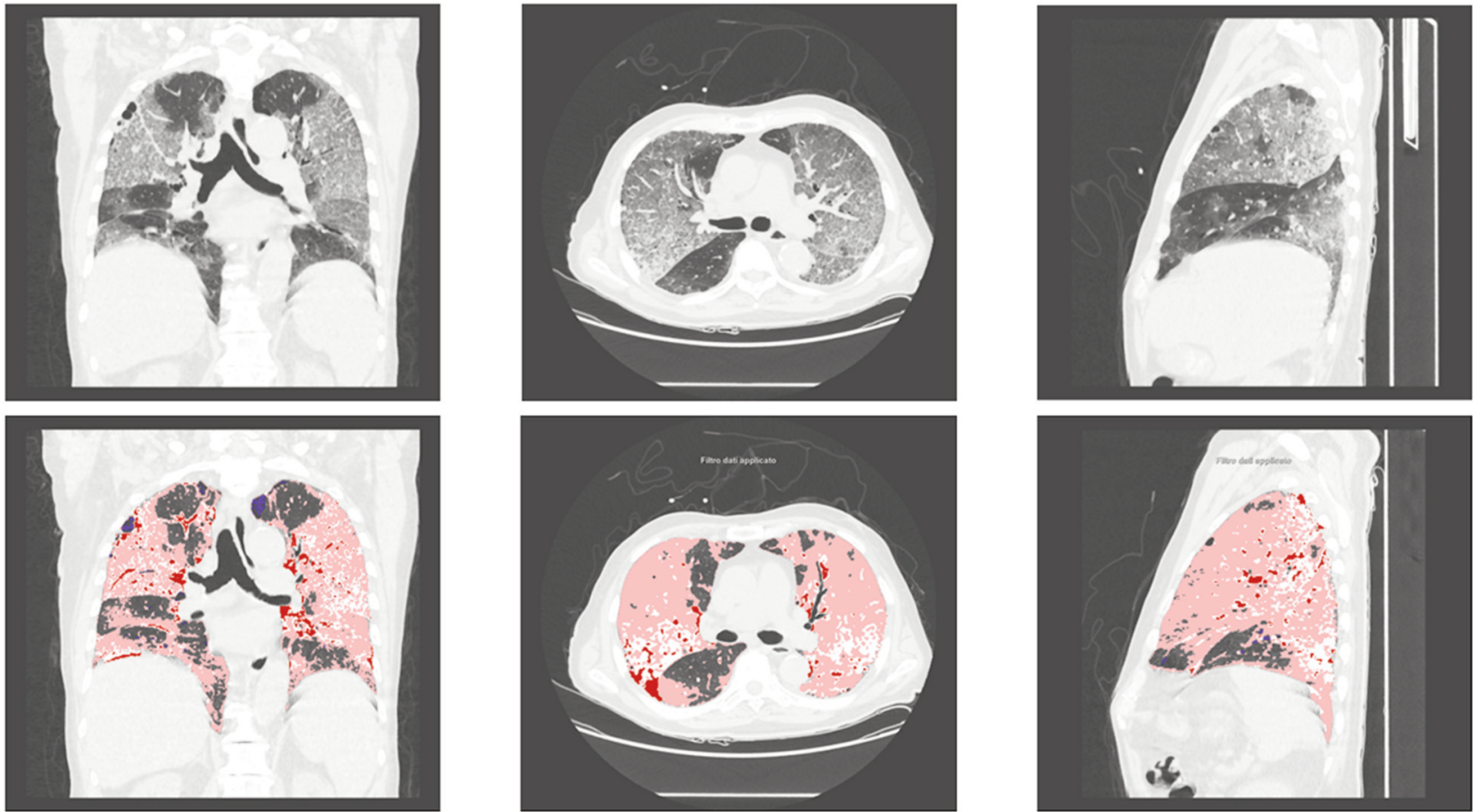

C

\begin{tabular}{|c|c|c|c|c|c|c|c|c|c|c|}
\hline & & & & & & & & & & Mar 042020 \\
\hline & \multirow[b]{2}{*}{ Color } & \multirow[b]{2}{*}{ HU } & \multicolumn{4}{|c|}{ Right lung } & \multicolumn{4}{|c|}{ Left lung } \\
\hline & & & Total & Upper & Middle & Lower & Total & Upper & Middle & Lower \\
\hline$-950 \mathrm{HU}$ & & $\begin{array}{c}{[-1024 /} \\
-977]\end{array}$ & $0.2193 \%$ & $0.3384 \%$ & $0.057 \%$ & $0.3356 \%$ & $0.1711 \%$ & $0.2334 \%$ & $0.0164 \%$ & $0.3053 \%$ \\
\hline \multirow[t]{5}{*}{$>-950 \mathrm{HU}$} & & $\begin{array}{c}{[-977 /} \\
.760]\end{array}$ & $28.7466 \%$ & $24.1524 \%$ & $35.0978 \%$ & $24.1325 \%$ & $19.5074 \%$ & $25.1359 \%$ & $7.4969 \%$ & $29.1527 \%$ \\
\hline & & $\begin{array}{c}{[-760 /} \\
-368]\end{array}$ & $47,2942 \%$ & $45,7446 \%$ & $46,8881 \%$ & $49,4278 \%$ & $61.2951 \%$ & $56,7648 \%$ & $73.0601 \%$ & $50.9029 \%$ \\
\hline & & $\begin{array}{l}{[-368 /} \\
-135]\end{array}$ & $17,3715 \%$ & $21,8312 \%$ & $12.0228 \%$ & $20,6681 \%$ & $15.0435 \%$ & $14,1112 \%$ & $14,7343 \%$ & $16,3263 \%$ \\
\hline & & $\begin{array}{c}{[-135 /} \\
40]\end{array}$ & $6.3685 \%$ & $7.9335 \%$ & $5.9344 \%$ & $5.436 \%$ & $3.9829 \%$ & $3.7547 \%$ & $4.6924 \%$ & $3.3128 \%$ \\
\hline & & Total & $2,1744 \mathrm{~L}$ & 0,6295 L & 0,9138 L & 0,6311 L & $1,8929 \mathrm{~L}$ & $0,5657 \mathrm{~L}$ & $0,7381 \mathrm{~L}$ & $0,589 \mathrm{~L}$ \\
\hline
\end{tabular}

Figure 2. Pre-processing (A) and post-processing color-coded (B) computed tomography (CT) images, reconstructed in coronal (left), axial (middle), and sagittal (right) plane, and software-based quantification of percentage of volume occupied by air (blue), normal parenchyma (black), groundglass opacity (pink), crazy paving (white), and consolidation(red) (C) of a 80 year-old male patient reaching the composite adverse outcome. Symptoms: fever, cough, and dyspnea. Smoking: no. Comorbidities: hypertension, coronary heart disease (CHD). Main laboratory findings: lymphocytes $=0.21 \mathrm{n} \times 10^{9} / \mathrm{l}(2.2 \%)$; lactate dehydrogenase $(\mathrm{LDH})=>500 \mathrm{U} / \mathrm{l} ; \mathrm{D}$-dimer N/A; eGFR=52 ml/min/1.73 $\mathrm{m}^{2}$. Comorbidity, age, lymphocytes, $\mathrm{LDH}$ (CALL) score: 13. Quantitative radiological score: total lungs $=22.2 \%$; upper lungs $=25.2 \%$; middle lungs=18.5\%; lower lungs $=25.6 \%$. Semiquantitative radiological score: total lungs $=58 ;$ upper lungs $=22 ;$ middle lungs=20; lower lungs $=16$.

\section{Results}

The main clinical and laboratory features of the 92 patients included in this analysis are presented in Table I. Median age was 63.0 years, $71.7 \%$ were males, $6.7 \%$ were current smokers, and $80.4 \%$ had at least one comorbidity (mean number of comorbidities in the whole cohort, 1.5 \pm 1.1 ). Representative HRCT scans are shown in Figures 1 and 2. The CT findings derived from the software-based, post-processing analysis and the semiquantitative evaluation of lung parenchyma are shown in Table II. Mean total percentage of crazy paving plus consolidation was $10.3 \%$; mean value increased from $7.7 \%$ in the upper lungs to $11.3 \%$ and $12.2 \%$ in the middle and lower lungs, respectively. Mean total semiquantitative score was 25.7 ; mean value increased from 7.4 in the upper lungs to 8.9 and 9.3 in the middle and lower lungs, respectively. Bilateral involvement and diffuse distribution were in $68.5 \%$ and $91.3 \%$ of patients, respectively, with ground-glass opacity observed in virtually all individuals and consolidation in almost two thirds of patients.

The two radiological scores correlated significantly with age, leucocyte count, D-dimer, and CALL score and inversely with percent lymphocytes and eGFR (Table III). The CALL score increased from the lowest to the highest 
Table II. Chest CT features of study subjects.

\begin{tabular}{|c|c|c|c|}
\hline \multicolumn{4}{|l|}{ Quantitative scoring } \\
\hline Variable & Right lung & Left lung & Both lungs \\
\hline Total lung volume & $2.7 \pm 4.1$ & $2.0 \pm 0.8$ & $4.6 \pm 4.5$ \\
\hline Upper lung volume & $0.5 \pm 0.2$ & $0.5 \pm 0.2$ & $1.0 \pm 0.4$ \\
\hline Middle lung volume & $0.9 \pm 0.3$ & $0.8 \pm 0.3$ & $1.7 \pm 0.5$ \\
\hline Lower lung volume & $0.8 \pm 0.4$ & $0.7 \pm 0.4$ & $1.5 \pm 0.7$ \\
\hline Percent total lung normal parenchyma & $60.6 \pm 24.5$ & $62.1 \pm 24.9$ & $61.3 \pm 24.0$ \\
\hline Percent total lung ground-glass opacity & $28.5 \pm 17.7$ & $28.1 \pm 18.1$ & $28.3 \pm 17.4$ \\
\hline Percent total lung crazy paving & $5.5 \pm 5.8$ & $4.8 \pm 5.5$ & $5.2 \pm 5.3$ \\
\hline Percent total lung consolidation & $5.3 \pm 9.2$ & $5.0 \pm 9.7$ & $5.1 \pm 8.7$ \\
\hline Percent total lung crazy paving+consolidation & $10.8 \pm 12.5$ & $9.8 \pm 14.1$ & $10.3 \pm 12.4$ \\
\hline Percent upper lung normal parenchyma & $62.9 \pm 27.8$ & $68.3 \pm 26.4$ & $65.6 \pm 25.4$ \\
\hline Percent upper lung ground-glass opacity & $28.2 \pm 20.4$ & $23.6 \pm 18.8$ & $25.9 \pm 18.9$ \\
\hline Percent upper lung crazy paving & $4.9 \pm 7.0$ & $3.5 \pm 6.5$ & $4.2 \pm 6.3$ \\
\hline Percent upper lung consolidation & $3.9 \pm 8.3$ & $3.2 \pm 9.9$ & $3.5 \pm 8.0$ \\
\hline Percent upper lung crazy paving+consolidation & $8.8 \pm 13.7$ & $6.6 \pm 15.2$ & $7.7 \pm 13.2$ \\
\hline Percent middle lung normal parenchyma & $60.8 \pm 25.0$ & $60.0 \pm 26.3$ & $60.4 \pm 24.8$ \\
\hline Percent middle lung ground-glass opacity & $27.0 \pm 18.3$ & $28.9 \pm 19.8$ & $28.0 \pm 18.2$ \\
\hline Percent middle lung crazy paving & $5.7 \pm 5.8$ & $5.3 \pm 5.9$ & $5.5 \pm 5.5$ \\
\hline Percent middle lung consolidation & $6.1 \pm 10.1$ & $5.6 \pm 9.6$ & $5.8 \pm 9.0$ \\
\hline Percent middle lung crazy paving+consolidation & $11.7 \pm 13.3$ & $11.0 \pm 14.4$ & $11.3 \pm 12.8$ \\
\hline Percent lower lung normal parenchyma & $56.8 \pm 27.5$ & $56.2 \pm 27.8$ & $56.5 \pm 26.4$ \\
\hline Percent lower lung ground-glass opacity & $30.6 \pm 20.3$ & $31.0 \pm 19.7$ & $30.8 \pm 19.0$ \\
\hline Percent lower lung crazy paving & $5.9 \pm 6.9$ & $5.9 \pm 6.7$ & $5.9 \pm 6.1$ \\
\hline Percent lower lung consolidation & $5.8 \pm 12.3$ & $6.8 \pm 14.4$ & $6.3 \pm 12.1$ \\
\hline Percent lower lung crazy paving+consolidation & $11.7 \pm 15.4$ & $12.6 \pm 18.6$ & $12.2 \pm 15.3$ \\
\hline \multicolumn{4}{|l|}{ Semiquantitative scoring } \\
\hline Variable & Value & Variable & Value \\
\hline Total lung score & $25.7 \pm 14.8$ & Monolateral involvement, n (\%) & $8(8.7)$ \\
\hline Upper lungs & $7.4 \pm 5.2$ & Bilateral involvement & $84(91.3)$ \\
\hline Score middle lungs & $8.9 \pm 5.8$ & Peripheral distribution, $\mathrm{n}(\%)$ & $28(30.4)$ \\
\hline Score lower lungs & $9.3 \pm 5.6$ & Central distribution, $\mathrm{n}(\%)$ & $1(1.1)$ \\
\hline Number of lung lobes involved & $4.4 \pm 1.3$ & Diffuse distribution, n (\%) & $63(68.5)$ \\
\hline Right upper lobe involvement, n (\%) & $82(89.1)$ & Ground-glass opacity, n (\%) & $88(95.7)$ \\
\hline Right middle lobe involvement, $\mathrm{n}(\%)$ & $74(80.4)$ & Crazy paving, $\mathrm{n}(\%)$ & $34(37.0)$ \\
\hline Right lower lobe involvement, $\mathrm{n}(\%)$ & $85(92.4)$ & Consolidation, $\mathrm{n}(\%)$ & $57(62.0)$ \\
\hline Left upper lobe involvement, n (\%) & $81(88.0)$ & Air bronchogram, n (\%) & $34(37.0)$ \\
\hline Left lower lobe involvement, $\mathrm{n}(\%)$ & $82(89.1)$ & Pleural effusion, $\mathrm{n}(\%)$ & $12(13.0)$ \\
\hline Mediastinum lymphadenopathy, n (\%) & $30(32.6)$ & Pericardial effusion, n (\%) & $19(20.7)$ \\
\hline
\end{tabular}

Data are mean \pm SD for continuous variables and $\mathrm{n}(\%)$ for categorical variables. CT: Computed tomography.

quartile of either total percentage of crazy paving plus consolidation or total semiquantitative score (Figure 3). Both scores were significantly higher in high-risk $v s$. low/intermediate-risk CALL score $(12.7 \pm 14.5$ vs. $6.7 \pm 7.2$,

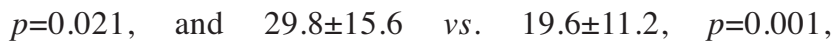
respectively). The quantitative and semiquantitative scores correlated also to each other as total $(\varrho=0.637, p<0.0001)$, upper $(\varrho=0.664, p<0.0001)$, middle $(\varrho=0.625, p<0.0001)$, and lower $(\varrho=0.574, p<0.0001)$ lung scores, though the correspondence between the two was not always very high.
At multivariate analysis, both the total percentage of crazy paving plus consolidation and the total semiquantitative score were independently associated with age, smoking, LDH and, inversely, eGFR; the quantitative, software-based score was associated also with diabetes. No independent association was observed between the two scores and gender, other comorbidities, percent lymphocytes, D-dimer, and CALL score (Table IV).

Twenty patients $(21.7 \%)$ required ICU admission (12 at entry and 8 during hospital stay) and 6 patients $(6.5 \%)$ died. 
Table III. Univariate correlations of the quantitative and semiquantitative radiological scores with selected demographic, clinical and laboratory features.

\begin{tabular}{|c|c|c|c|c|}
\hline \multirow[t]{2}{*}{ Variables } & \multicolumn{2}{|c|}{$\begin{array}{l}\text { Percent total crazy paving } \\
+ \text { consolidation }\end{array}$} & \multicolumn{2}{|c|}{ Total lung score } \\
\hline & $P$ & $p$-Value & $\varrho$ & $p$-Value \\
\hline Age & 0.361 & $<0.0001$ & 0.261 & 0.012 \\
\hline Hemoglobin & -0.126 & 0.232 & -0.105 & 0.320 \\
\hline Platelet count & 0.068 & 0.519 & 0.053 & 0.613 \\
\hline Leucocyte count & 0.252 & 0.015 & 0.284 & 0.006 \\
\hline Lymphocyte count & -0.151 & 0.152 & -0.169 & 0.108 \\
\hline Lymphocytes \% & -0.285 & 0.006 & -0.333 & 0.001 \\
\hline D-dimer & 0.340 & 0.002 & 0.292 & 0.007 \\
\hline Fibrinogen & 0.188 & 0.077 & 0.227 & 0.032 \\
\hline eGFR & -0.324 & 0.002 & -0.391 & $<0.0001$ \\
\hline CALL score & 0.395 & $<0.0001$ & 0.396 & $<0.0001$ \\
\hline
\end{tabular}

eGFR: Estimated glomerular filtration rate; CALL: comorbidity, age, lymphocytes, LDH.

The composite adverse outcome of ICU admission and/or death occurred in 24 patients $(26.1 \%, 23$ males), who were older and had a higher prevalence of any comorbidity, obesity, diabetes, hypertension, dyspnea, and abnormal CK MB, hs-cTn I, BNP, and lipase levels, higher CALL score, lower prevalence of symptoms for more than 4 days, and lower eGFR, as compared with no-ICU/no-death individuals (Table I). Moreover, ICU/death patients had higher total, upper, middle, and lower quantitative and semiquantitative (except in lower lungs) score than no-ICU/no-death individuals (Figure 4).

Both the quantitative $[\mathrm{HR}=1.05(95 \% \mathrm{CI}=1.01,1.09)$, $p=0.010]$ and the semiquantitative [1.04 (1.01-1.08), $p=0.010]$ scores were significantly associated with the composite adverse outcome. When sequentially adjusted for confounders in multivariate analysis, the quantitative, but not the semiquantitative score remained independently associated with the composite outcome. Other independent correlates of ICU/death were obesity, hypertension, high LDH levels, CALL and, only in the models including the total semiquantitative score, the CALL score (Table V).

\section{Discussion}

Previous observations have shown that chest CT findings correlate with several clinical and laboratory features that characterize NCIP, including fever, increased erythrocyte sedimentation rate, C-reactive protein, pro-calcitonin, $\mathrm{LDH}$, and decreased lymphocyte count $(18,19)$. Our study confirms and extends these data by showing that grade of CT findings, as assessed by two different scoring systems, was independently associated with age, smoking, $\mathrm{LDH}$, and (for the quantitative score only) the presence of diabetes and, inversely, with eGFR. In addition, the two radiological scores were found to correlate with D-dimer and the CALL score at
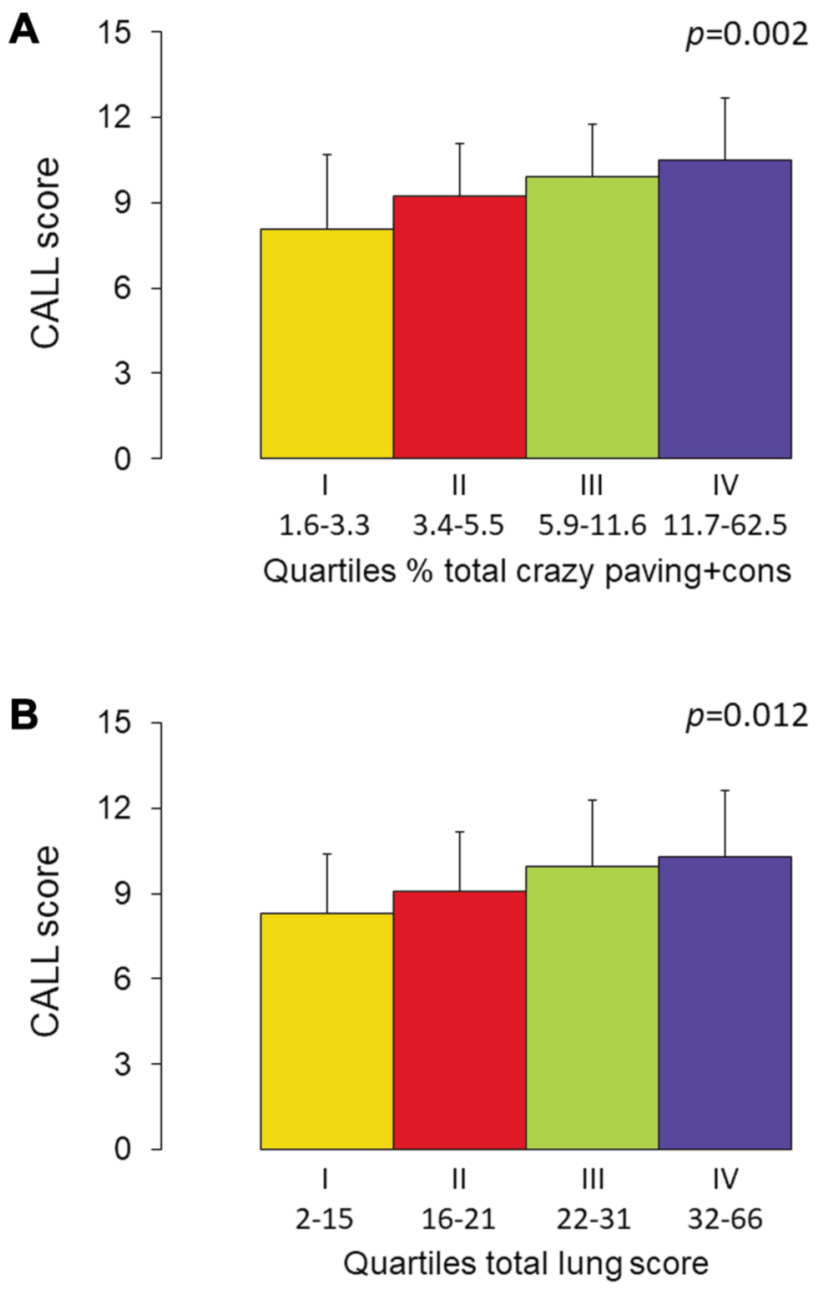

Figure 3. CALL score by quartiles of quantitative (A) and semiquantitative $(B)$ radiological score. CALL: Comorbidity, age, lymphocytes, LDH. 
A

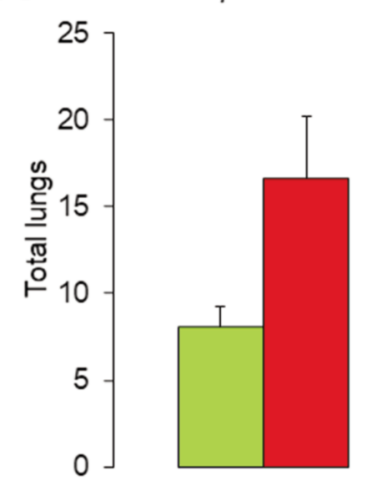

B

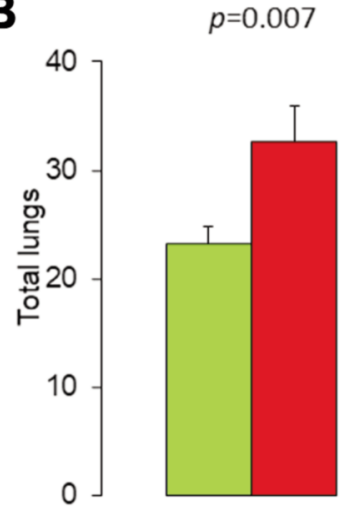

$p=0.006$

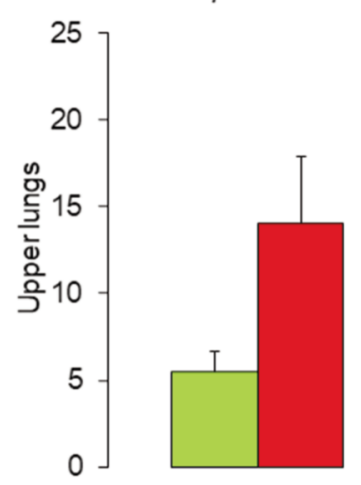

$P<0.0001$

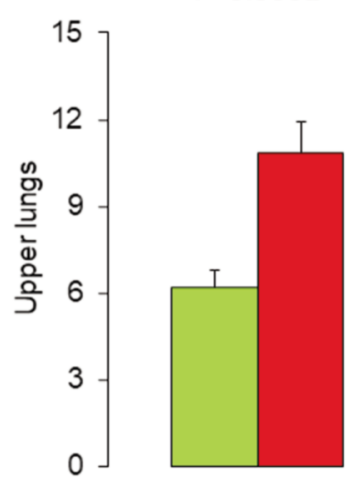

$p=0.016$

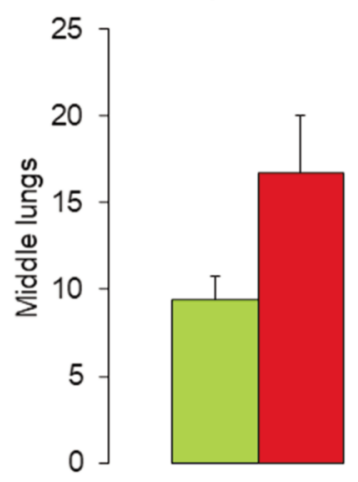

$p=0.019$

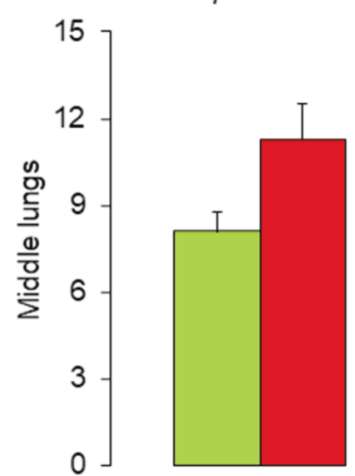

$p=0.004$

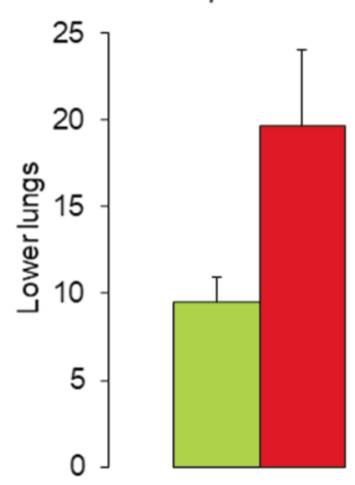

$p=0.066$

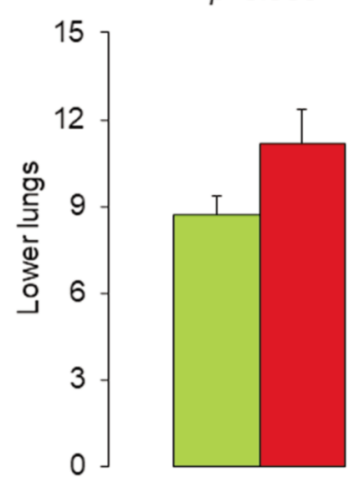

Figure 4. Quantitative (A) and semiquantitative $(B)$ radiological scores, total, upper, middle, and lower lungs, in patients not reaching (green) and reaching (red) the composite adverse outcome.

univariate analysis. These findings indicate the importance of hypercoagulability, renal dysfunction, and other comorbidities in patients with NCIP, supporting the concept that these conditions may favor disease progression in these individuals (20). Hypercoagulability, as evidenced by a characteristic elevation of D-Dimer levels, may result in thrombosis associated with microvascular injury in the lungs, thus increasing the severity of lung involvement (21). Moreover, impaired renal function and other comorbidities, including diabetes, have been shown to me more prevalent in patients with severe or lethal NCIP than in those without $(22,23)$.

More importantly, our data showed that the grade of severity of CT findings was associated with a composite adverse outcome, together with a known risk factor for disease progression such male gender, comorbidities (obesity and hypertension), and high LDH levels, thus supporting the use of CT scoring algorithms, combined with clinical and laboratory parameters, for predicting outcome in patients with NCIP (24). These findings are consistent with previous reports showing that grading the extent and severity of lung involvement on CT scans using different scoring methods is able to predict disease exacerbation $(25,26)$ and outcome $(10-12,27)$ in COVID-19 patients. Several studies $(28,29)$ and a meta-analysis $(30)$ have in fact shown that radiological scores are higher in patients with critical than in those with non-critical illness. However, in our study, the correlation between the two radiological scores, the quantitative and the semiquantitative, were not as high as in previous studies using the same (11) or a different (31) semiquantitative scoring method. Moreover, though both radiological scores were associated with the composite adverse outcome in the unadjusted analysis, only the quantitative, software-based score remained an independent predictor of ICU admission/death in the adjusted models. This is a variance with a previous report showing that this specific semiquantitative scoring method was capable to predict mortality (11).

Our study also showed that the two radiological scores correlated with a novel clinical score for predicting disease progression, the CALL score (13), though the association was not observed in the multivariable analysis. In addition, we found that the CALL score was associated with the composite 
Table IV. Independent correlates of the quantitative and semiquantitative scores (multivariable linear regression analysis with backward selection of variables).

\begin{tabular}{|c|c|c|c|c|c|c|c|c|c|c|}
\hline Model & \multicolumn{2}{|c|}{1} & \multicolumn{2}{|c|}{2} & \multicolumn{2}{|c|}{3} & \multicolumn{2}{|c|}{4} & \multicolumn{2}{|c|}{5} \\
\hline \multicolumn{11}{|c|}{ Total percentage of crazy paving plus consolidation } \\
\hline Covariate & Beta & $p$-Value & Beta & $p$-Value & Beta & $p$-Value & Beta & $p$-Value & Beta & $p$-Value \\
\hline Age & 0.196 & 0.012 & - & - & - & - & - & - & NA & NA \\
\hline Gender & - & - & - & - & - & - & - & - & - & - \\
\hline Smoking & 13.144 & 0.010 & 15.314 & 0.004 & - & - & - & - & 14.969 & 0.005 \\
\hline N. comorbidities & - & - & - & - & NA & NA & NA & NA & NA & NA \\
\hline Obesity & NA & NA & NA & NA & - & - & - & - & NA & NA \\
\hline Hypertension & NA & NA & NA & NA & - & - & - & - & NA & NA \\
\hline Diabetes & NA & NA & NA & NA & 12.914 & $<0.0001$ & 14.875 & $<0.0001$ & NA & NA \\
\hline CHD & NA & NA & NA & NA & - & - & - & - & NA & NA \\
\hline COPD & NA & NA & NA & NA & - & - & - & - & NA & NA \\
\hline Oncological dis. & NA & NA & NA & NA & - & - & - & - & NA & NA \\
\hline Hematological dis. & NA & NA & NA & NA & - & - & & & NA & NA \\
\hline$\%$ lymphocytes & NA & NA & - & - & NA & NA & -0.198 & 0.046 & NA & NA \\
\hline $\mathrm{LDH}>500 \mathrm{U} / 1$ & NA & NA & 4.005 & 0.048 & NA & NA & 4.352 & 0.030 & NA & NA \\
\hline D-dimer & NA & NA & - & - & NA & NA & - & - & - & - \\
\hline eGFR & NA & NA & -0.178 & 0.002 & NA & NA & -0.184 & 0.002 & -0.221 & $<0.0001$ \\
\hline CALL score & NA & NA & NA & NA & NA & NA & NA & NA & - & - \\
\hline \multicolumn{11}{|l|}{ Total lung score } \\
\hline Covariate & Beta & $p$-Value & Beta & $p$-Value & Beta & $p$-Value & Beta & $p$-Value & Beta & $p$-Value \\
\hline Age & 0.238 & 0.012 & - & - & 0.238 & 0.012 & - & - & NA & NA \\
\hline Gender & - & - & - & - & - & - & - & - & - & - \\
\hline Smoking & - & - & 16.998 & 0.001 & - & - & 12.712 & 0.028 & $12.018-$ & $<0.0001$ \\
\hline N. comorbidities & - & - & - & - & NA & NA & NA & NA & NA & NA \\
\hline Obesity & NA & NA & NA & NA & - & - & - & - & NA & NA \\
\hline Hypertension & NA & NA & NA & NA & - & - & - & - & NA & NA \\
\hline Diabetes & NA & NA & NA & NA & - & - & - & - & NA & NA \\
\hline CHD & NA & NA & NA & NA & - & - & - & - & NA & NA \\
\hline COPD & NA & NA & NA & NA & - & - & - & - & NA & NA \\
\hline Oncological dis. & NA & NA & NA & NA & - & - & - & - & NA & NA \\
\hline Hematological dis. & & & & & & & - & - & & \\
\hline$\%$ lymphocytes & NA & NA & - & - & NA & NA & - & - & NA & NA \\
\hline $\mathrm{LDH}>500 \mathrm{U} / 1$ & NA & NA & 8.493 & $<0.0001$ & NA & NA & 8.082 & $<0.0001$ & NA & NA \\
\hline D-dimer & NA & NA & - & - & NA & NA & - & - & - & - \\
\hline eGFR & NA & NA & -0.199 & 0.002 & NA & NA & -0.167 & 0.008 & -0.253 & $<0.0001$ \\
\hline CALL score & NA & NA & NA & NA & NA & NA & NA & NA & - & - \\
\hline
\end{tabular}

CHD: Coronary heart disease; COPD: chronic obstructive pulmonary disease; LDH: lactate dehydrogenase; eGFR: estimated glomerular filtration rate; CALL: comorbidity, age, lymphocytes, $\mathrm{LDH}$.

adverse outcome independently of the two radiological scores, thus confirming the role of the variables used for calculating this score (comorbidity, age, lymphocytes, and LDH) as predictors of disease severity and mortality $(22,23,32,33)$.

Strengths of this study include the use of two different scoring methods for grading chest CT findings and the availability of a wide range of clinical and laboratory data. This study has several limitations. First, the study sample was relatively small. Second, patients had a wide range of comorbidities that may have affected laboratory features and the composite adverse outcome independently of the severity of NCIP. Finally, CT scans were obtained only at baseline, thus not allowing the assessment of the association between changes in CT findings with disease exacerbation and the composite outcome.

\section{Conclusion}

In conclusion, in NCIP patients, two different radiological scores correlated with each other and with several clinical 
Table V. Independent correlates of the quantitative and semiquantitative scores (multivariable linear regression analysis with backward selection of variables).

\begin{tabular}{|c|c|c|c|c|c|c|c|c|c|c|}
\hline \multirow{2}{*}{$\begin{array}{l}\text { Model } \\
\text { Covariate }\end{array}$} & \multicolumn{2}{|l|}{1} & \multicolumn{2}{|l|}{2} & \multicolumn{2}{|l|}{3} & \multicolumn{2}{|l|}{4} & \multicolumn{2}{|l|}{5} \\
\hline & OR $(95 \% \mathrm{CI})$ & $p$-Value & OR $(95 \% \mathrm{CI})$ & $p$-Value & OR $(95 \% \mathrm{CI})$ & $p$-Value & OR $(95 \% \mathrm{CI})$ & $p$-Value & OR $(95 \% \mathrm{CI})$ & $p$-Value \\
\hline Total \% CP+Cons & $\begin{array}{c}1.05 \\
(1.00,1.09)\end{array}$ & 0.036 & $\begin{array}{c}1.06 \\
(1.00,1.11)\end{array}$ & 0.049 & $\begin{array}{c}1.06 \\
(1.01,1.11)\end{array}$ & 0.015 & $\begin{array}{c}1.05 \\
(1.00,1.09)\end{array}$ & 0.041 & $\begin{array}{c}1.04 \\
(1.00,1.09)\end{array}$ & 0.048 \\
\hline Age & - & - & - & - & - & - & - & - & NA & NA \\
\hline Smoking & - & - & - & - & - & - & - & - & - & - \\
\hline N. comorbidities & - & - & - & - & NA & NA & NA & NA & NA & NA \\
\hline Obesity & NA & NA & NA & NA & 15.56 & $\begin{array}{c}0.039 \\
1.15,209.86)\end{array}$ & ) & - & NA & NA \\
\hline Hypertension & NA & NA & NA & NA & 3.54 & $\begin{array}{c}0.028 \\
(1.15,10.93)\end{array}$ & - & - & NA & NA \\
\hline Diabetes & NA & NA & NA & NA & - & - & - & - & NA & NA \\
\hline CHD & NA & NA & NA & NA & - & - & - & - & NA & NA \\
\hline COPD & NA & NA & NA & NA & - & - & - & - & NA & NA \\
\hline Oncological dis. & NA & NA & NA & NA & - & - & - & - & NA & NA \\
\hline Hematological dis. & NA & NA & NA & NA & - & - & - & - & NA & NA \\
\hline$\%$ lymphocytes & NA & NA & - & - & NA & NA & - & - & NA & NA \\
\hline $\mathrm{LDH}>500 \mathrm{U} / 1$ & NA & NA & 9.57 & $\begin{array}{c}0.012 \\
(1.65,550.46)\end{array}$ & NA & NA & 7.59 & $\begin{array}{c}\mathrm{NA} \\
(1.27,45.35)\end{array}$ & $\begin{array}{c}\text { NA } \\
0.026\end{array}$ & \\
\hline D-dimer & NA & NA & - & - & NA & NA & - & - & - & - \\
\hline eGFR & NA & NA & - & - & NA & NA & - & - & - & - \\
\hline CALL score & NA & NA & NA & NA & NA & NA & NA & NA & $\begin{array}{c}1.46 \\
(1.05,2.02)\end{array}$ & 0.024 \\
\hline Covariate & OR $(95 \% \mathrm{CI})$ & $p$-Value & OR $(95 \% \mathrm{CI})$ & $p$-Value & OR $(95 \% \mathrm{CI})$ & $p$-Value & OR $(95 \% \mathrm{CI})$ & $p$-Value & OR $(95 \% \mathrm{CI})$ & $p$-Value \\
\hline Total lung score & $\begin{array}{c}1.03 \\
(1.00,1.07)\end{array}$ & 0.043 & - & - & $\begin{array}{c}1.04 \\
(1.01,1.08)\end{array}$ & 0.023 & - & - & - & - \\
\hline Age & - & - & - & - & - & - & - & - & NA & NA \\
\hline Smoking & - & - & - & - & - & - & - & - & - & - \\
\hline N. comorbidities & $\begin{array}{c}1.63 \\
(1.02,2.60)\end{array}$ & 0.041 & - & - & NA & NA & NA & NA & NA & NA \\
\hline Obesity & NA & NA & NA & NA & $\begin{array}{c}15.12 \\
(1.12,203.65)\end{array}$ & 0.041 & - & - & NA & NA \\
\hline Hypertension & NA & NA & NA & NA & $\begin{array}{c}3.22 \\
(1.08,9.63)\end{array}$ & 0.036 & - & - & NA & NA \\
\hline Diabetes & NA & NA & NA & NA & - & - & - & - & NA & NA \\
\hline CHD & NA & NA & NA & NA & - & - & - & - & NA & NA \\
\hline COPD & NA & NA & NA & NA & - & - & - & - & NA & NA \\
\hline Oncological dis. & NA & NA & NA & NA & - & - & - & - & NA & NA \\
\hline Hematological dis. & NA & NA & NA & NA & - & - & - & - & NA & NA \\
\hline \% lymphocytes & NA & NA & - & - & NA & NA & - & - & NA & NA \\
\hline $\mathrm{LDH}>500 \mathrm{U} / 1$ & NA & NA & $\begin{array}{c}15.58 \\
(2.79,87.17)\end{array}$ & 0.002 & NA & NA & $\begin{array}{c}15.58 \\
(2.79,87.17)\end{array}$ & 0.002 & NA & NA \\
\hline D-dimer & NA & NA & - & - & NA & NA & - & - & - & - \\
\hline eGFR & NA & NA & - & - & NA & NA & - & - & - & - \\
\hline CALL score & NA & NA & NA & NA & NA & NA & NA & NA & $\begin{array}{c}1.63 \\
(1.19,2.24)\end{array}$ & 0.003 \\
\hline
\end{tabular}

OR: Odds ratio; $\mathrm{CI}$ : confidence interval; total \% CP+Cons: total percentage of crazy paving plus consolidation; CHD: coronary heart disease; COPD: chronic obstructive pulmonary disease; LDH: lactate dehydrogenase; eGFR: estimated glomerular filtration rate; CALL: comorbidity, age, lymphocytes, LDH.

and laboratory features and were significantly associated with the CALL score in univariate, but not in multivariate analysis. The quantitative score worked better than the semiquantitative score as an independent predictor of a composite adverse outcome including ICU admission and/or death, beyond clinical and laboratory features that are associated with COVID-19 progression and the CALL score. 


\section{Conflicts of Interest}

The Authors declare no conflicts of interest regarding this study.

\section{Authors' Contributions}

Study conception and design: Gianluca Vanni, Stefano Rizza, Alfonso Bellia, and Marcello Chiocchi.

Collection and analysis of data: Luca Pugliese, Francesco Paolo Sbordone, Francesco Grimaldi, Marco Materazzo and Marco Pellicciaro. Manuscript writing: Luca Pugliese, Francesca Ricci and Federica DI Tosto. Manuscript editing: Gianluca Vanni, Stefano Rizza, Alfonso Bellia, Roberto Floris, Francesco Garaci, and Marcello Chiocchi. Interpretation of data: Gianluca Vanni, Roberto Floris, Francesco Garaci, and Marcello Chiocchi. Critical revision and draft approval: Luca Pugliese, Francesco Paolo Sbordone, Francesco Grimaldi, Francesca Ricci, Federica Di Tosto, Luigi Spiritigliozzi, Carlo Di Donna, Matteo Presicce, Vincenzo De Stasio, Leonardo Benelli, Francesca D’Errico, Monia Pasqualetto, Jacopo Maria Legramante, Marco Materazzo, Marco Pellicciaro, Oreste Claudio Buonomo, Gianluca Vanni, Stefano Rizza, Alfonso Bellia, Roberto Floris, Francesco Garaci, and Marcello Chiocchi.

\section{References}

1 WHO I Novel Coronavirus - China. Available at: https:// www.who.int/csr/don/12-january-2020-novel-coronaviruschina/en/ [Last accessed September 16, 2020].

2 WHO Coronavirus Disease (COVID-19) Dashboard I WHO Coronavirus Disease (COVID-19) Dashboard. Available st: https://covid19.who.int/ [last accessed September 16, 2020].

3 World Health Organization (WHO): WHO director-generals' opening remarks at the media briefing on COVID-19 - 11 March 2020. Available at: https://www.who.int/dg/speeches/detail/whodirector-general-s-opening-remarks-at-the-media-briefing-oncovid-19-11-march-2020 [Last accessed September 16, 2020].

4 Zhu N, Zhang D, Wang W, Li X, Yang B, Song J, Zhao X, Huang B, Shi W, Lu R, Niu P, Zhan F, Ma X, Wang D, Xu W, Wu G, Gao GF and Tan W: A novel coronavirus from patients with pneumonia in China, 2019. N Engl J Med 382: 727-733, 2020. PMID: 31978945. PMID: 31978945. DOI: 10.1056/NEJMoa2001017

5 Chung M, Bernheim A, Mei X, Zhang N, Huang M, Zeng X, Cui J, Xu W, Yang Y, Fayad ZA, Jacobi A, Li K, Li S and Shan H: CT imaging features of 2019 novel coronavirus (2019NCoV). Radiology 295: 202-207, 2020. PMID: 32017661. DOI: 10.1148/radiol.2020200230

6 Kim H, Hong $\mathrm{H}$ and Yoon SH: Diagnostic performance of CT and reverse transcriptase polymerase chain reaction for coronavirus disease 2019: A meta-analysis. Radiology 296: E145-E155, 2020. PMID: 32301646. DOI: 10.1148/radiol. 2020201343

7 Ai T, Yang Z, Hou H, Zhan C, Chen C, Lv W, Tao Q, Sun Z and Xia L: Correlation of chest CT and RT-PCR testing for Coronavirus disease 2019 (COVID-19) in China: A report of 1014 cases. Radiology 296: E32-E40, 2020. PMID: 32101510. DOI: $10.1148 /$ radiol.2020200642

8 He JL, Luo L, Luo ZD, Lyu JX, Ng MY, Shen XP and Wen Z: Diagnostic performance between CT and initial real-time RTPCR for clinically suspected 2019 coronavirus disease (COVID-
19) patients outside Wuhan, China. Respir Med 168, 2020. PMID: 32364959. DOI: 10.1016/j.rmed.2020.105980

9 Cheng Z, Qin L, Cao Q, Dai J, Pan A, Yang W, Gao Y, Chen L and Yan F: Quantitative computed tomography of the coronavirus disease 2019 (COVID-19) pneumonia. Radiol Infect Dis 7: 55-61, 2020. PMID: 32346594. DOI: 10.1016/j.jrid.2020.04.004

10 Colombi D, Bodini FC, Petrini M, Maffi G, Morelli N, Milanese G, Silva M, Sverzellati N and Michieletti E: Well-aerated lung on admitting chest CT to predict adverse outcome in COVID-19 Pneumonia. Radiology 296: E86-E96, 2020. PMID: 32301647. DOI: $10.1148 /$ radiol.2020201433

11 Yuan M, Yin W, Tao Z, Tan W and Hu Y: Association of radiologic findings with mortality of patients infected with 2019 novel coronavirus in Wuhan, China. PLoS One 15, 2020. PMID: 32191764. DOI: 10.1371/journal.pone.0230548

12 Zhang K, Liu X, Shen J, Li Z, Sang Y, Wu X, Zha Y, Liang W, Wang C, Wang K, Ye L, Gao M, Zhou Z, Li L, Wang J, Yang Z, Cai H, Xu J, Yang L, Cai W, Xu W, Wu S, Zhang W, Jiang S, Zheng L, Zhang X, Wang L, Lu L, Li J, Yin H, Wang W, Li O, Zhang C, Liang L, Wu T, Deng R, Wei K, Zhou Y, Chen T, Lau JYN, Fok M, He J, Lin T, Li W and Wang G: Clinically applicable AI System for accurate diagnosis, quantitative measurements, and prognosis of COVID-19 pneumonia using computed tomography. Cell 181: 1423-1433.e11, 2020. PMID: 32416069. DOI: 10.1016/j.cell.2020.04.045

13 Ji D, Zhang D, Xu J, Chen Z, Yang T, Zhao P, Chen G, Cheng G, Wang Y, Bi J, Tan L, Lau G and Qin E: Prediction for progression risk in patients with COVID-19 pneumonia: the CALL Score. Clin Infect Dis 71, 2020. PMID: 32416069. DOI: 10.1016/j.cell.2020.04.045

14 Organizzazione dei Pronto Soccorso e dei Percorsi Paziente Nella Fase 2 della Pandemia Covid-19. Available at: https://www.simeu.it/w/download/get/0/2020_05_11_SIMEU_C ovid19_Organizzazione_PS_Fase2.pdf/download/articoli/4071 [Last accessed September 16, 2020].

15 Thoracic VCAR I GE Healthcare. Available at: https://www. gehealthcare.com/products/advanced-visualization/allapplications/thoracic-vcar [Last accessed September 16, 2020].

16 Austin JHM, Müller NL, Friedman PJ, Hansell DM, Naidich DP, Remy-Jardin M, Webb WR and Zerhouni EA: Glossary of terms for CT of the lungs: Recommendations of the Nomenclature Committee of the Fleischner Society. Radiology 200: 327-331, 1996. PMID: 8685321. DOI: 10.1148/radiology.200.2.8685321

17 Ye Z, Zhang Y, Wang Y, Huang Z and Song B: Chest CT manifestations of new coronavirus disease 2019 (COVID-19): a pictorial review. Eur Radiol 30: 4381-4389, 2020. PMID: 32193638. DOI: 10.1007/s00330-020-06801-0

18 Xiong Y, Sun D, Liu Y, Fan Y, Zhao L, Li X and Zhu W: Clinical and high-resolution CT features of the COVID-19 Infection: Comparison of the initial and follow-up changes. Invest Radiol 55: 332-339, 2020. PMID: 32134800. DOI: 10.1097/RLI.0000000000000674

19 Wu J, Wu X, Zeng W, Guo D, Fang Z, Chen L, Huang H and Li C: Chest CT findings in patients with coronavirus disease 2019 and its relationship with clinical features. Invest Radiol 55: 257-261, 2020. PMID: 32091414. DOI: 10.1097/RLI.0000000000000670

20 Wang T, Du Z, Zhu F, Cao Z, An Y, Gao Y and Jiang B: Comorbidities and multi-organ injuries in the treatment of COVID-19. Lancet 395: e52, 2020. PMID: 32171074. DOI: 10.1016/S0140-6736(20)30558-4 
21 Ackermann M, Verleden SE, Kuehnel M, Haverich A, Welte T, Laenger F, Vanstapel A, Werlein CMD, Stark H, Tzankov A, Li WW, Li VW, Mentzer SJ and Jonigk D: Pulmonary vascular endothelialitis, thrombosis, and angiogenesis in Covid-19. N Engl J Med 383: 120-128, 2020. PMID: 32437596. DOI: 10.1056/NEJMoa2015432

22 Richardson S, Hirsch JS, Narasimhan M, Crawford JM, McGinn T, Davidson KW, Barnaby DP, Becker LB, Chelico JD, Cohen SL, Cookingham J, Coppa K, Diefenbach MA, Dominello AJ, Duer-Hefele J, Falzon L, Gitlin J, Hajizadeh N, Harvin TG, Hirschwerk DA, Kim EJ, Kozel ZM, Marrast LM, Mogavero JN, Osorio GA, Qiu M and Zanos TP: Presenting characteristics, comorbidities, and outcomes among 5700 patients hospitalized with COVID-19 in the New York City area. JAMA - J Am Med Assoc 323: 2052-2059, 2020. PMID: 32320003. DOI: 10.1001/ jama.2020.6775

23 Zheng Z, Peng F, Xu B, Zhao J, Liu H, Peng J, Li Q, Jiang C, Zhou Y, Liu S, Ye C, Zhang P, Xing Y, Guo H and Tang W: Risk factors of critical \& mortal COVID-19 cases: A systematic literature review and meta-analysis. J Infect 81: e16-e25, 2020. PMID: 32335169. DOI: 10.1016/j.jinf.2020.04.021

24 Liang W, Liang H, Ou L, Chen B, Chen A, Li C, Li Y, Guan W, Sang L, Lu J, Xu Y, Chen G, Guo H, Guo J, Chen Z, Zhao Y, Li $\mathrm{S}$, Zhang N, Zhong N and He J: Development and validation of a clinical risk score to predict the occurrence of critical illness in hospitalized patients with COVID-19. JAMA Intern Med 180: 1081-1089, 2020. PMID: 32396163. DOI: 10.1001/jamaintern med.2020.2033

25 Liu J, Chen T, Yang H, Cai Y, Yu Q, Chen J, Chen Z, Shang Q$\mathrm{L}, \mathrm{Ma} \mathrm{C}$, Chen $\mathrm{X}$ and Xiao E: Clinical and radiological changes of hospitalised patients with COVID-19 pneumonia from disease onset to acute exacerbation: a multicentre paired cohort study. Eur Radiol 30: 5702-5708, 2020. PMID: 32385648. DOI: 10.1007/s00330-020-06916-4

26 Fu F, Lou J, Xi D, Bai Y, Ma G, Zhao B, Liu D, Bao G, Lei Z and Wang $M$ : Chest computed tomography findings of coronavirus disease 2019 (COVID-19) pneumonia. Eur Radiol 30, 2020. PMID: 32435925. DOI: 10.1007/s00330-020-06920-8

27 Yu Q, Wang Y, Huang S, Liu S, Zhou Z, Zhang S, Zhao Z, Yu Y, Yang Y and Ju S: Multicenter cohort study demonstrates more consolidation in upper lungs on initial CT increases the risk of adverse clinical outcome in COVID-19 patients. Theranostics 10: 5641-5648, 2020. PMID: 32373237. DOI: 10.7150/thno. 46465
28 Liu Z, Jin C, Wu CC, Liang T, Zhao H, Wang Y, Wang Z, Li F, Zhou J, Cai S, Zeng L and Yang J: Association between initial chest $\mathrm{CT}$ or clinical features and clinical course in patients with coronavirus disease 2019 Pneumonia. Korean J Radiol 21: 736745, 2020. PMID: 32410412. DOI: 10.3348/kjr.2020.0171

29 Li B, Li X, Wang Y, Han Y, Wang Y, Wang C, Zhang G, Jin J, Jia H, Fan F, Ma W, Liu H and Zhou Y: Diagnostic value and key features of computed tomography in Coronavirus Disease 2019. Emerg Microbes Infect 9: 787-793, 2020. PMID: 32241244. DOI: $10.1080 / 22221751.2020 .1750307$

30 Fu L, Wang B, Yuan T, Chen X, Ao Y, Fitzpatrick T, Li P, Zhou Y, Lin Y fan, Duan Q, Luo G, Fan S, Lu Y, Feng A, Zhan Y, Liang B, Cai W, Zhang L, Du X, Li L, Shu Y and Zou H: Clinical characteristics of coronavirus disease 2019 (COVID-19) in China: A systematic review and meta-analysis. J Infect 80 : 656-665, 2020. PMID: 32283155. DOI: 10.1016/j.jinf.2020. 03.041

31 Shen C, Yu N, Cai S, Zhou J, Sheng J, Liu K, Zhou H, Guo Y and Niu G: Quantitative computed tomography analysis for stratifying the severity of Coronavirus Disease 2019. J Pharm Anal 10: 123-129, 2020. PMID: 32292624. DOI: 10.1016/ j.jpha.2020.03.004

32 Chen G, Wu D, Guo W, Cao Y, Huang D, Wang H, Wang T, Zhang X, Chen H, Yu H, Zhang X, Zhang M, Wu S, Song J, Chen T, Han M, Li S, Luo X, Zhao J and Ning Q: Clinical and immunological features of severe and moderate coronavirus disease 2019. J Clin Invest 130: 2620-2629, 2020. PMID: 32217835. DOI: $10.1172 / J C I 137244$

33 Tian W, Jiang W, Yao J, Nicholson CJ, Li RH, Sigurslid HH, Wooster L, Rotter JI, Guo X and Malhotra R: Predictors of mortality in hospitalized COVID-19 patients: A systematic review and meta-analysis. J Med Virol, 2020. PMID: 32441789. DOI: $10.1002 / j m v .26050$
Received September 16, 2020

Revised September 23, 2020

Accepted September 24, 2020 